\title{
La literatura en Quimantú: una revolución incómoda ${ }^{1}$
}

\section{Literature in Quimantú: an uncomfortable revolution}

\author{
CHRISTIAN ANWANDTER DONOSO ${ }^{a}$ \\ ${ }^{a}$ Universidad Adolfo Ibáñez, Facultad de Artes Liberales. Chile. \\ Correo electrónico: christian.anwandter@uai.cl
}

\begin{abstract}
Proponemos una reflexión sobre las colecciones literarias de la Editora Nacional Quimantú durante el gobierno de la Unidad Popular, entendiéndolas como parte de las tensiones existentes entre un imperativo revolucionario y otro económico. La valoración de la literatura y la conformación de un canon literario internacional se vinculan con el propósito democratizador propio de Quimantú, pero también con la configuración política del gobierno de la Unidad Popular y las divergencias del campo cultural en torno al rol que debían jugar los intelectuales en la creación de una nueva cultura. La utopía de una sociedad sin clases revela, al mismo tiempo, la atracción y la incomodidad de la clase intelectual frente al nuevo lector popular que emerge. El paratexto de los libros de literatura ofrece una escena para la expresión de distintas posturas en torno a la relación entre literatura y revolución, al mismo tiempo que se proponen al lector modos de lectura literaria afines a los cambios políticos, sociales y culturales promovidos por el gobierno.
\end{abstract}

Palabras claves: Quimantú, literatura, canon, revolución, lector popular.

We present a reflection on the literary collections published by the Editora Nacional Quimantú during the Unidad Popular government, understanding them as part of the tensions existing between a revolutionary imperative and an economical one. The appreciation of literature and the elaboration of an international literary canon are related to the democratic purpose characteristic of Quimantú, but they also relate to the political configuration of the Unidad Popular's government and the differences existing in the cultural field concerning the role intellectuals should have in the creation of a new culture. The utopia of a classless society reveals, at the same time, the attraction and the discomfort intellectuals felt towards the new popular reader that emerges. Paratext in literary books offer a scene for the expression of different positions concerning the relationship between literature and revolution, while different literary reading models, closely linked to the political, social and cultural changes being promoted by the government, are proposed to the reader.

Key words: Quimantú, literature, canon, revolution, popular reader.

${ }^{1}$ Este artículo hace parte del proyecto Fondecyt Regular "Literatura durante la Unidad Popular en Chile", $\mathrm{N}^{\circ} 1180595$, cuyo investigador responsable es Matías Ayala. 


\section{INTRODUCCIÓN}

Con la compra de Zig-Zag por parte del Estado el 12 de febrero de 1971, comienza la historia de la Editora Nacional Quimantú. Considerada como una de las políticas socioculturales más relevantes del gobierno de la Unidad Popular, Quimantú (o "Sol del saber" en mapuzungún) es también un hito en la historia del libro en Chile. No solo por el volumen de libros publicados -inédito para el país-, sino también porque esta masificación apuntaba a sectores populares ${ }^{2}$, habitualmente ignorados por el mercado editorial. Quimantú tuvo tres colecciones dedicadas a literatura para público general: Quimantú para todos, Minilibros y Cordillera. ${ }^{3}$ Según Bergot (2004), entre el 4 de noviembre de 1971 y el 11 de septiembre de 1973, estas colecciones habían publicado un total de 6.235 .000 libros -lo que representa un poco más del 50\% del total de libros impresos por la editorial-, distribuidos en 121 títulos diferentes y 118 autores publicados. ${ }^{4}$

La publicación de obras literarias fue parte esencial del quehacer de Quimantú, por lo que nos preguntamos acerca del sentido de esta línea editorial. Sería ingenuo pensar que estas colecciones ofrecieron un acceso a un ente abstracto llamado literatura, cuya esencia sería invariable. Conviene pensar estas colecciones como resultado de una serie de decisiones y definiciones tomadas por comunidades de práctica (Bowker y Star, 2000) conformadas por individuos. Así como Latour y Woolgar (1996) demuestran que la publicación de conocimiento científico es resultado de una producción enunciativa efectuada por integrantes de comunidades de especialistas, entendemos las colecciones literarias de Quimantú como "agente canonizador" (Carrasco, Procesos de canonización: 143) que mediante un determinado diseño del objeto libro, la conformación de una colección o la elaboración discursiva paratextual, plasman una determinada manera de entender, pensar y valorar la literatura. El resultado de esta producción de lo literario tiende a acercar a la literatura el horizonte revolucionario, proponiendo modos de lectura en que se valora lo popular y se critica la sociedad burguesa. Esta literatura -la publicada por la editorial del Estado- busca afianzar el vínculo con el lector popular y proponer modelos de aproximación a las obras literarias

\footnotetext{
${ }^{2}$ Si bien se suele recordar como un antecedente de Quimantú el anteproyecto de Editorial del Estado presentado por Allende en 1967, se omite que la argumentación en favor de esta editorial se basa fundamentalmente en el mal uso del financiamiento público del proyecto de la Enciclopedia Chilena a través de la Editorial Jurídica, que buscaba, en línea con las políticas desarrollistas de décadas anteriores, ofrecer a los legisladores y autoridades políticas información acerca de los recursos del país de manera de que pudieran tomar las mejores decisiones. Mientras que el objetivo de la Enciclopedia Chilena era elaborar una obra monumental que permitiera el desarrollo económico del país a través del apoyo prestado a la elite política, la Editorial del Estado propuesta en 1967 por Allende mostraba ya su interés en abaratar costos para así ir "en beneficio de las capas modestas de la población".

${ }^{3}$ Dejamos afuera, en esta ocasión, colecciones como Cuncuna o revistas de literatura infantil.

${ }^{4}$ La colección que más libros imprimió y publicó fue Minilibros, con 3.780 .000 ejemplares y 55 títulos. Le sigue Quimantú para todos, con 2.252.000 ejemplares y 48 títulos y la colección Cordillera, bastante más pequeña, con 203.000 ejemplares para 18 títulos (cf. Bergot). El género más representativo fue la narrativa (novela y cuento), aunque también se publicaron libros de poesía, crónica, entre otros.
} 
coherentes con la mirada política de la UP. Las colecciones literarias complejizan el lugar de la literatura en la construcción de una nueva sociedad y de un hombre nuevo, alejándola de la función de entretención y del reconocimiento de la tradición como valor estético transhistórico. La literatura emerge como objeto de disputa entre campos ideológicos que se enfrentan ante un público lector inédito al que se busca conquistar.

\section{DEMOCRATIZACIÓN DEL LIBRO: ENTRE EL IMPERATIVO COMERCIAL Y LA REVOLUCIÓN}

Como señala Austin, es necesario vincular estrechamente Quimantú con los programas de alfabetización impulsados durante el gobierno de Allende, así como con la reforma de la Escuela Nacional Unificada (ENU), que buscaba articular un sistema educativo para acompañar a lo largo de toda la vida a los ciudadanos (136-137). La editorial del Estado tendría un rol fundamental como proveedor de textos educativos. Quimantú, por lo tanto, implica no solo la producción de libros y su democratización, sino también un proyecto transformador del conjunto de la sociedad en que la cultura impresa (diarios, revistas, libros, etc.) estaba llamada a jugar un rol central.

La editorial estatal puede ser considerada como una herramienta para la construcción de una conciencia socialista. Para lograr esta subjetivación, era necesario romper el encantamiento ideológico de los productos culturales del capitalismo, en la medida en que estos producían una conciencia alienada y reproductora de la desigualdad social y colonial. Bowen señala que este deseo de ruptura puede leerse como un "ambicioso programa inmunológico destinado a reforzar la cobertura crítica que mediaría entre los individuos o grupos sociales y los mensajes o representaciones sociales circundantes" (4). ${ }^{5}$ Pero si bien lo inmunológico puede ser un aspecto relevante, el horizonte era la instauración de un "Hombre Nuevo", dándole así un sentido teleológico y demiúrgico al proyecto cultural de la UP que revelaba, también, su necesaria insuficiencia, puesto que esa nueva cultura solo emergería después del proceso de transformaciones que se iniciaba.

Quimantú, al mismo tiempo, se despliega en un escenario económico capitalista. Bergot explica que, aunque la editorial pertenecía al "área social" y era dependiente de la CORFO -su accionista mayoritario con el 90\% de su capital- era independiente en términos de gestión y operaba como una empresa más en el mercado, prestando además

\footnotetext{
${ }^{5}$ Un lúcido ejemplo de este tipo de crítica la encontramos en Para leer al Pato Donald, de Ariel Dorfman y Ariel Mattelart, ambos colaboradores de Quimantú. Particularmente interesante en nuestro caso es el de Ariel Dorfman, que abordaba el problema de la literatura y su relación con los medios de comunicación de masas en la Revista de Educación, o críticas a la literatura infantil o revistas como Readers Digest en los primeros números de la Revista Chilena de Literatura de la Universidad de Chile ( $c f$. Dorfman 2016). Mattelart, también, a través de sus intervenciones en revistas como los Cuadernos de realidad nacional, daba cuenta de la preocupación por darle un rol revolucionario a los medios de comunicación, entendiendo el riesgo político de que estos permanecieran en manos de los adversarios políticos de la Unidad Popular (cf. Zarowsky 2009).
} 
servicios de imprenta (9). ${ }^{6}$ Molina rescata testimonios que enfatizan la constante presión financiera que pendía sobre Quimantú, afectada también por el incumplimiento por parte de CORFO a los pagos de deuda contraída por Zig-Zag (51-57). Lo comercial, de esta forma, tenía incidencia en las decisiones editoriales que se tomaban.

Así, la revolución -con lo que ella conlleva de destrucción de un determinado orden- debía al mismo tiempo someterse a un régimen de valoración impuesto por aquello que se intentaba dejar en el pasado. El deseo revolucionario sometido al orden económico vigente refleja la tensión que recorrió el gobierno de la UP y que, al mismo tiempo, constituía su marca propia, la idea de una revolución dentro de cauces institucionales, de una progresiva evolución institucional que daría paso, sin violencia, a un nuevo tipo de sociedad. Esto hizo que, en vez de que se evaluara la producción editorial en Quimantú de acuerdo a objetivos planteados por el proyecto político de la UP, muchas veces se enfatizaran sus logros comerciales. ${ }^{7}$ Si bien es posible suponer que las ventas de Quimantú implicaban un compromiso político o un proceso de subjetivación socialista exitoso, la equivalencia evade el problema de la falta de huellas de la supuesta subjetivación producida mediante la lectura. ${ }^{8}$

Un ejemplo de estas tensiones la podemos ver en avisos de la colección Minilibros que aparecían en revistas como El Jinete Fantasma (El Manque) y Dimensión Cero. ${ }^{9}$ Estos parecen apelar a un consumidor de aventuras y folletines románticos, más que a un lector popular crítico de las estrategias publicitarias del capitalismo y adherente de la revolución. Como podemos ver en la figura 1, abajo a la izquierda aparece, en horizontal, el nombre de la colección, el nombre de la editorial, y dos cualidades: “...entretienen y emocionan!”. Más arriba, leemos: "todo el AMOR y la PASIÓN... todo el MISTERIO y la AVENTURA", que utiliza mayúsculas y negritas para reforzar la importancia de los sustantivos. Aún más arriba, y como naciendo de la palabra 'pasión', vemos un libro abierto por la mitad. En su portada se ve nuevamente el nombre de la colección y una imagen circular de un hombre y una mujer abrazándose. Más arriba, y cada vez con mayor amplitud de la imagen, se aprecia una pareja besándose. El lenguaje publicitario se proyecta en el libro y este, a su vez, se

\footnotetext{
${ }^{6}$ Así, Quimantú ofrecía sus servicios de impresión a revistas como Ercilla, Selecciones del Reader's Digest, Disneylandia, Tío Rico, Tribilín, Visión, entre otras (Molina et al. 2018: 31). Esto muestra que algunas de las empresas a las que Quimantú prestaba servicios eran oponentes a la UP.

7 Volodia Teitelboim, en un texto llamado "5.000.000 de libros", revela esta asociación directa entre éxito de ventas y desarrollo revolucionario, como si uno y otro fueran indisociables: "(...) Quimantú vendió su primer millón. Fue el millón del despegue. Porque en la mitad de ese plazo vendió el segundo millón. En febrero debe llegar a los 5 millones de ejemplares. Es una hazaña de los trabajadores que los hacen. Pero también es signo inequívoco que por dentro del espíritu de Chile anda una revolución (...)" (2).

${ }^{8}$ A propósito de la imposibilidad de conocer en detalle cómo fueron recibidos los libros de Quimantú debido a la destrucción de archivos tras el Golpe de Estado de 1973, Bergot seńala la necesidad de tener cautela ante a la inexistencia de documentación para conocer el funcionamiento de la distribución, así como de los posibles cambios en comportamientos de lectura en la población (16).

${ }^{9}$ Esta publicidad, con sus variantes, se encuentra por ejemplo en los números 52 y 53 de la revista Dimensión cero, y en los números 241, 242, 244, 245, 248, 250 del Jinete fantasma.
} 
proyecta hacia la vida misma. El mensaje es evidente: al leer los Minilibros, la vida misma se llena de pasión.

Figura 1. Aviso publicitario de la colección Minilibros de Quimantú.

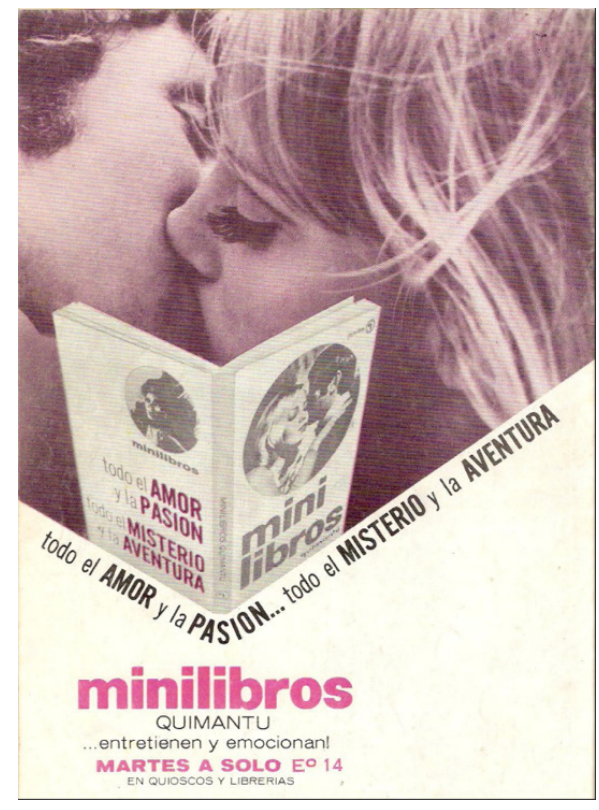

Los medios publicitarios para promocionar los Minilibros parecen contradecir el espíritu crítico de la propuesta cultural del gobierno de Allende. ¿En qué medida estos avisos se distancian de aquellos productos del capitalismo que la UP criticaba? ¿Se trata de una disonancia irrelevante en el seno de Quimantú o bien de una estrategia para capturar lectores acostumbrados a cierto tipo de producto para así luego ofrecerles algo ideológicamente diferente? Joaquín Gutiérrez, en entrevista con el semanario Chile Hoy, revelaba que la nueva colección Minilibros, para "atraer" al mayor público posible, buscaba asimilarse a la literatura folletinesca, ayudando así a "realizar el tránsito de la subcultura a formas más elevadas de literatura" (21). El aviso sería entonces el reflejo de esta estrategia camaleónica $-\mathrm{y}$ hasta cierto punto predadora- que permitiría que un consumidor de una colección como la de Corín Tellado pudiera, mediante la semejanza, adquirir un libro de literatura más bien realista de Quimantú. Otra respuesta posible la encontramos en los testimonios rescatados por Molina et al. (2018), quien subraya la incomunicación existente entre divisiones y secciones provocada por el acelerado ritmo de trabajo (39). En cualquier caso, proponemos entender el aviso como resultado del estatuto paradójico de Quimantú, a la vez empresa de mercado y promotora de la revolución socialista. 


\section{EMANCIPACIÓN CULTURAL E INTERNACIONALIZACIÓN}

La literatura, según la perspectiva de la izquierda de la época, podía contribuir al proceso revolucionario o fortalecer la influencia del capitalismo y de la cultura de sus potencias. El tema se plantea en los debates del Congreso Nacional de Educación de diciembre de 1971, publicados por la Revista de Educación en marzo de 1972. El Ministerio de Educación afirma que la sociedad chilena está afectada por una "extranjerización cultural", señalando que "nuestros alumnos conocen al dedillo los aspectos históricos, geográficos, literarios y artísticos de otras naciones, especialmente de las metrópolis occidentales, pero desconocen aspectos significativos de la realidad nacional" (73). No se trata, según el documento que serviría de base al proyecto de la ENU, de un repliegue identitario, sino de "asimilar críticamente todas las tendencias histórico-culturales, [lo que] tenderá a rescatar y a reponer en primer plano nuestro ser nacional y latinoamericano, hasta ahora postergado, escondido o deformado por la monstruosa extranjerización cultural que ha traído consigo el régimen del capitalismo dependiente" (79). La editorial del Estado, señalaba el documento, vendría a rectificar esta situación, poniendo a disposición de los estudiantes los textos que permitirían esa asimilación crítica y la recuperación identitaria de lo nacional y latinoamericano.

Uno esperaría que esa prioridad dada a lo nacional y lo latinoamericano se reflejara en la conformación de las colecciones literarias de Quimantú. Sin embargo, del total de títulos publicados (224), solo 39 corresponden a autores nacionales. Subercaseaux llama la atención sobre el hecho de que, en la colección Minilibros, de los 55 títulos publicados, solo 6 corresponden a autores nacionales y 6 a autores latinoamericanos. La mayor parte de los autores publicados son europeos (23 títulos), estadounidenses (12 títulos) y soviéticos (8 títulos), lo que evidenciaría un criterio de conformación de colección contradictorio (Subercaseaux, Historia del libro 149). ${ }^{10}$ Como bien lo explica Bergot, la disponibilidad de derechos de autor (después de 30 años de fallecido el autor, según la ley de propiedad intelectual de la época) explica en parte el criterio de selección de las colecciones de literatura, aunque también incidieron la calidad literaria y la cercanía de los autores con ideas socialistas y comunistas (19). Por otra parte, Marinello (2007) apunta a que la colección Nosotros los chilenos sería la encargada de dar a conocer la realidad nacional, proponiendo un "'espejo' de la nación" (10) en que se articula cultura popular y cultura ilustrada.

Las colecciones de literatura no respondían, entonces, a la lógica de la emancipación cultural entendida como el proceso de revertir la "extranjerización". Quimantú plantea

\footnotetext{
10 También sorprende que el país más representado en la colección sea Estados Unidos, aunque sería un error asumir que la pertenencia nacional tiene una equivalencia política. Aun así, Bianchi señala que el gusto por la cultura norteamericana en Chile era minoritario en los años sesenta, probablemente por motivos políticos como la intervención en Vietnam o el boicot a Cuba. Bianchi interpreta la progresiva apertura a lo norteamericano como un acercamiento que permitió establecer diálogos múltiples con expresiones de los medios de comunicación de masas. En este sentido, la incorporación de escritores norteamericanos al catálogo de las colecciones literarias de Quimantú puede hacer parte de esta nueva apertura provocada por los cambios en los medios de comunicación.
} 
una visión internacional de la literatura promovida desde el Estado, sin cuestionar estructuralmente la "república de las letras" (Casanova 2008), es decir, las jerarquías de circulación internacional de la literatura. ${ }^{11}$ Prevalece así el planteamiento del Partido Comunista que ve en la cultura burguesa un patrimonio universal reapropiable (Berríos 2003; Groys 2008). La presencia de autores soviéticos, si bien se podría considerar como un cambio en las jerarquías tradicionales, refleja la intensificación de las relaciones durante los gobiernos de Frei y de Allende entre Chile y la URSS, y su lugar de potencia mundial durante la Guerra Fría. Por otra parte, esta internacionalización es acotada en términos de género -casi todos los autores publicados son hombres- y en términos históricos, puesto que casi la totalidad de las obras publicadas pertenecen al siglo XIX y XX, es decir, corresponde a obras posteriores a la transición histórica de régimen de las bellas artes a la literatura (Schaeffer 1983), lo que también coincide con la independencia de gran parte de los países latinoamericanos.

Más allá de la discusión en torno al rol de la literatura en el proceso de revolución socialista de la UP, Quimantú rompe con el paradigma nacionalista en la difusión estatal de la literatura. Esto supone redefinir el rol del Estado en relación con la literatura, pasando de un rol patrimonial de rescate de lo literario nacional a un rol educativo, donde la literatura internacional es una forma -entre otras, por cierto- de fortalecer un espíritu crítico ante la realidad y nivelar las insuficiencias en el capital cultural de la población. Es tal vez la primera vez en Chile en que la literatura es concebida, desde la política cultural, en relación con el efecto liberador que produce en el lector más que en la conservación de obras literarias nacionales mediante la conformación de una memoria compartida. Quimantú no está preocupada de generar una memoria, sino más bien una conciencia.

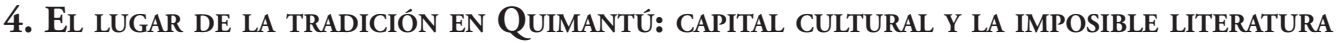 DE PARTIDO}

En una entrevista que el periodista Jorge Jobet hace a Luciano Rodrigo, director del Departamento Editorial de Quimantú, en el diario La Nación, del 22 de abril de 1972,

\footnotetext{
${ }^{11}$ También cabe distinguir la internacionalización literaria de Quimantú de un fenómeno como el boom de la literatura latinoamericana en los ańos 60. Según Ángel Rama, el boom había logrado reemplazar al público de élite por el público global de los mass media. Según Rama, este desplazamiento transformó al escritor en un "empresario independiente" que tenía que "publicitarse para conquistar al público" (108). La masificación lectora del boom no implicó una mayor autonomía de los escritores respecto del mercado, sino que su subordinación. En este sentido, Rama se lamenta de que, en tiempos de "vastas audiencias" los escritores latinoamericanos "pertenecen a todos, pero no pertenecen a nadie" (110). Quimantú, que intentaba incorporar a la cultura impresa a los sectores populares repensando también el rol de los medios de comunicación como instrumento de subjetivación política, no busca capitalizar las expectativas que existían sobre el horizonte revolucionario latinoamericano en el extranjero, ni subordinó, al menos en las colecciones literarias, la figura de escritor a operaciones publicitarias de alcance global o hispanoamericano. En efecto, Quimantú apunta fundamentalmente al mercado nacional, por lo que no busca exportar sus libros o publicitar en el extranjero la literatura chilena.
} 
este distingue las dos colecciones de literatura existentes a la fecha. Aunque ambas buscan "permitir una difusión mucho más amplia de los valores literarios", la colección Quimantú para todos busca "llegar a vastos sectores con obras de alto valor literario, pero de fácil comprensión, libros que no exigen del lector una preparación previa" (3-4). La colección "Cordillera", en cambio, era concebida para "obras con un lenguaje más depurado, que en cierto modo exigen alguna cultura literaria de parte del lector". ${ }^{12} \mathrm{Al}$ mismo tiempo, esta apertura a lo popular se traducía simultáneamente en volúmenes de impresión mucho más altos.

En el ámbito de los bienes culturales, las colecciones de literatura implicaban poner a disposición de la mayoría aquello que antes solo era accesible a algunos. Se buscaba "reparar desigualdades pasadas en el acceso y distribución del capital cultural" (Subercaseaux, Historia de las ideas 154). Esto ya se planteaba en el Programa Básico de Gobierno de la Unidad Popular, donde se indica que la creación de una cultura nueva solo podrá surgir "por el acceso de las masas populares al arte, la literatura y los medios de comunicación contra su comercialización” (28). Tomás Moulian, integrante del equipo de División Editorial de Quimantú, a cargo del departamento de Libros, interpretaba esta labor de Quimantú como un proceso de "dignificación de los pobres", (López 100), mientras que uno de los asesores literarios de Quimantú, Alfonso Calderón, ponía en valor la relación que se estableció entre "la masa y el libro al alcance de todos" (López 100).

Esta compensación o reparación no implica necesariamente, sin embargo, un cambio de estatuto sobre el valor cultural otorgado a las obras literarias pertenecientes a la tradición. Se puede dar acceso a una obra literaria a un público popular y masivo, y que esa obra literaria opere como signo y valor de un determinado orden cultural que no se modifica. El desafío era introducir la literatura al lector popular para la creación de una nueva cultura, más que para el reconocimiento de valores estéticos asociados a la cultura burguesa imperante. Groys, por ejemplo, muestra hasta qué punto la unidad políticoestética producida bajo Stalin en la URSS permitió la emergencia del realismo socialista. Los bolcheviques, según Groys, consideraban que para la construcción del hombre nuevo y para llevar adelante la revolución socialista, era necesario tomar "lo mejor" y "lo útil" de la cultura mundial (87). James (1973), por su parte, quien propone pensar el realismo socialista no como una invención de Stalin, Zhdánov y Gorki, sino como un movimiento global con derivaciones locales surgido de la influencia de Marx, Lenin y de los movimientos proletarios, propone tres conceptos de origen leninista que pueden ayudarnos a entender también la apreciación de la literatura en Quimantú: naródnost, klássovost y partiinost, que respectivamente designan la relación entre el arte y el pueblo o lo popular, el arte y las clases sociales y, por último, la relación entre el arte y el partido (1-14). El realismo socialista, en tanto, emanaba de la necesidad de alineamiento e identificación con el partido

${ }^{12}$ De hecho, a juzgar por una entrevista realizada en el año 2003 a Germán Marín sobre la publicación de Fuegos artificiales en la colección Cordillera, menciona que esta era considerada una colección de "élite", "un poco semirreaccionaria" (Cisternas 85). Podríamos inferir que, en la época, la eficacia política de las colecciones de literatura se medía por su capacidad de ser acogida fácilmente por el segmento de lectores populares. 
y, particularmente en el contexto de la URSS, con Stalin. El concepto de partiinost permitía a la producción literaria convertirse en literatura de partido, tal como Lenin lo preconizara en su texto "La organización del Partido y la Literatura de Partido", publicado en 1905.

En este sentido, la vía 'chilena' al socialismo, tanto por la falta de unidad políticoestética en la cúspide del poder, como por percibirse como un proceso revolucionario 'gradual', no podía exigir un alineamiento ideológico estricto. Esta misma indefinición ideológica implicaba no ocupar una posición clara con respecto al pasado que permitiera repensar la tradición en relación a las necesidades de una nueva cultura. No se observa entonces una reapropiación de la literatura para la creación de lo nuevo, sino más bien un modo de lectura que acompaña el proceso revolucionario. Podríamos proponer que la lógica de la compensación refleja la conciencia de pertenencia a una élite intelectual por parte de los responsables de Quimantú en un intento de igualar el terreno en el campo del capital cultural, pero no una reapropiación de la tradición post-histórica como la que efectuó la cultura estaliniana.

Llegar a los sectores populares era el punto de consenso en torno a la política cultural. Como señalaba el Encargado Nacional de Cultura del Partido Comunista, Carlos Maldonado, en “¿Dónde está la política cultural?”, para el gobierno de la UP, "la cultura parece ser como la quinta rueda del coche y al parecer no hay conciencia de que lo anterior refleja una carencia en la batalla ideológica" (1972a: 12). Carencia ideológica desde el punto de vista de la radicalidad del objetivo político, pero también expresión de un pluralismo propio de la democracia aún vigente. Maldonado abogaba por formas participativas que dieran lugar a la expresión cultural del pueblo, más que a una responsabilidad de los intelectuales en la difusión de la cultura. En "Proceso cultural como incentivador de la praxis", Maldonado acusa también de atentar contra el proceso cultural a "aquellos que en su nombre aparecen como sus mejores espadachines", a saber, el "sector intelectual que visualiza la revolución cultural como un acto voluntarista, entendiendo el mundo de la conciencia en cuanto sólo a su autonomía. Tratan, por ejemplo, de dotar de un poder que no tienen (y nunca alcanzarán) a los factores semánticos, los eslogan (sic) publicitarios, los personajes de historietas o de telenovelas" (1972b: 74-75). Se trata de una clara crítica a la labor de Dorfman y Mattelart y de aquellas líneas editoriales de Quimantú más comprometidas con la transformación de contenidos culturales. Maldonado planteaba que aquello que tenía mejores resultados económicos eran productos afines a la sociedad burguesa, mientras que publicaciones como Cabro Chico, que buscaron subvertir valores tradicionales de la literatura infantil, no tuvieron buenos resultados. ${ }^{13}$ De ahí también su crítica al Taller de

\footnotetext{
${ }^{13}$ La revista Cabro chico se concebía explícitamente en oposición a “'cómics' norteamericanos, envasados en México, para el consumo de nińos latinos, con personajes y situaciones na' que ver con nuestro modo de vida, que muchas veces fomentan la violencia, la maldad y la pillería en las relaciones humanas" (López: 18). Así, publicaba cuentos clásicos, levemente alterados, en que se veía a Caperucita cantando "Venceremos" o al Gato con Botas "perdonando a sus ofensores y abrazando la causa de los pobres del campo" (López: 41). Sin embargo, esta manipulación explícita de cuentos tradicionales tuvo un efecto negativo en las ventas. Carlos Maldonado, en tanto, señalaba que la estrategia de subvertir valores burgueses era equivalente a "recrear signos negativos" y
} 
escritores de la Unidad Popular, que parecía otorgarse un lugar central en los organismos de poder sin cuestionar la autonomía de los sectores intelectuales (Zamorano 2016).

Lo que el gobierno de la UP no resolvió era qué lugar darle tanto a los intelectuales como a los sectores populares en la creación de la nueva cultura, cuánto debían dirigir los primeros a los segundos y cuánto espacio se podía dar a los últimos en la medida en que carecían de conocimientos considerados necesarios. En relación con el documento publicado en la revista Cormorán "Por la creación de una cultura popular y nacional", Enrique Lihn (1997) daba cuenta de la dificultad para un grupo de escritores adherentes al gobierno de la UP para validar su postura ante otros militantes de izquierda, mencionando al mismo tiempo el riesgo de que el pueblo fuera sometido "a una andanada de ediciones completas de autores nacionales o clásicos universales", lo que podría suceder si predominaba "una actitud paternalista, como la suposición de que habría una cultura lista para ser envasada, etiquetada y distribuida, y que sólo faltaría ponerla al alcance de las masas" (438). Mientras Maldonado toma distancia de ciertas prácticas de Quimantú por ingenuas, Lihn cuestiona la eficacia de distribuir literatura sin una adecuada mediación.

En este escenario en que se deslegitiman distintas aproximaciones a la política cultural, en que incluso la distribución de lo literario, a pesar de su masividad, se cuestiona, se percibe la ausencia de una instancia política que zanje el debate, y por lo mismo la necesaria pluralidad de aproximaciones al problema. Quimantú es el lugar institucional de expresión de esta diversidad de miradas sobre la política cultural. Es a la vez un lugar de democratización de la cultura, de revolución cultural y una instancia de negociación en torno al rol de la cultura en la construcción socialista impulsada en la UP. Quimantú es la expresión del 'realismo socialista' a la chilena.

\subsection{Leer la revolución en la literatura: el rol del paratexto}

Aparte de entrevistas y testimonios, no hay archivos que nos permitan indagar en torno a la postura editorial sobre la literatura o los criterios para conformar las colecciones. La descripción de la colección Quimantú para todos, que acompañaba sus ejemplares, decía que esta nacía "dirigida a satisfacer una amplia necesidad cultural: la de ofrecer lo mejor de la literatura chilena, latinoamericana y universal de todas las épocas a precios al alcance de nuestro pueblo, abriéndole así una ancha ventana hacia la vida". Si bien se alude a la "necesidad cultural" de ofrecer acceso a lo mejor de la literatura, no se explicitan las causas de las cuales se deriva esa necesidad. Es difícil entender cómo se pensaba el rol del libro de literatura en relación con el lector al que se pensaba llegar, cómo se articulaba la "necesidad cultural" con el propósito perseguido. ${ }^{14}$

que esto, como estrategia, era un error, puesto que lo que se necesitaba era traducir e imaginar mundos en que estos nuevos valores se desplegaran ("El proceso cultural..." 79).

${ }^{14}$ Los libros de literatura dependían del Departamento Editorial, a su vez subordinada a la División Editorial a cargo de Joaquín Gutiérrez. La línea editorial, según testimonio de Luciano Rodrigo, se fijaba a través de 
A pesar de que no tenemos registros acerca de la recepción efectiva de las colecciones literarias de Quimantú, sí podemos analizar aquello que se deseaba y entendía acerca del lector al que estaban destinados los distintos libros. Con este fin, proponemos analizar elementos paratextuales como prólogos, textos de presentación e introducción de obras literarias que trazan gestos, expectativas y deseos acerca del modo de recepción de las obras publicadas. ${ }^{15}$ Estos textos cumplen una doble función. Por una parte, familiarizar al lector con la obra que leerá. Es decir, darle información sobre el autor, su contexto y su obra, a grandes rasgos. Por otra, proponen un determinado marco de lectura. Es en este punto donde aparecen valores sobre lo literario que reflejan una mirada estética cercana al proyecto político de la UP. ${ }^{16}$ Se conforma así un "género discursivo" (Bajtín 2012) que remite al campo intelectual adherente a la UP y que, por su inscripción en la editorial del Estado, modela institucionalmente lo literario, sus modos de leerla e interpretarla. Este discurso ensaya diversas formas de transferencia cultural y de apropiación de la tradición, reflejando la diversidad de miradas en torno a la política cultural que caracteriza al gobierno de la UP.

Así, es común encontrar en los paratextos de obras literarias de Quimantú una valoración de lo popular. En el libro La captura, de Edesio Alvarado, se afirma que este "es una proposición de conocimiento del alma y de la tierra del sur de Chile" (5). En este caso, es la obra misma que refleja ese conocimiento, pero en algunos casos encontramos que se subraya igualmente el conocimiento que el autor tiene del mundo popular. Es lo que sucede con Alfonso Alcalde -director de la colección Nosotros los chilenos- que al publicar Las aventuras de El Salustio y El Trúbico, es presentado a los lectores como alguien para quien "Los trabajadores del carbón, los pescadores artesanales del litoral, los humildes subproletarios que transitan por los barrios marginales de la ciudad son (...) conocidos íntimos y de siempre" (5). Esta información sobre el autor se presenta también en la contraportada del libro, reforzando así su importancia.

Esta valoración de lo popular se acompaña de una condena del capitalismo y de la burguesía. Ya sea en La risa roja, de Andreiev, donde "los seres constituyen juguetes de un sistema, peones del ajedrez" (5), o en Bartleby, de Melville, donde el personaje del "preferiría no hacerlo" se presenta como quien determina "no obedecer las órdenes de su empleador (...) en muda contemplación del muro de ladrillos que se levantaba frente a las ventanas de la oficina en una calle de Wall Street" (6), el paratexto tiende a subrayar la oposición entre

reuniones de comité lideradas por Gutiérrez y a las que asistían también Alfonso Calderón (asesor literario), Ariel Dorfman, Luis Domínguez, entre otros. Según Rodrigo, era fundamental la opinión de Gutiérrez, del Partido Comunista, para la selección de los títulos a publicar (Molina et al. 41-42). A pesar de esta descripción, no tenemos acceso a los argumentos utilizados o a las formas de dirimir diferencias de opinión como para evaluar el alcance de las políticas editoriales de las colecciones literarias de Quimantú.

${ }^{15}$ Genette (2001) define al paratexto como "aquello por lo cual un texto se hace libro y se propone como tal a sus lectores, y, más generalmente, al público. Más que de un límite o de una frontera cerrada, se trata aquí de un umbral (...) que ofrece a quien sea la posibilidad de entrar o retroceder" (7).

${ }^{16}$ En ocasiones, estos textos son anónimos, en otras son firmadas con iniciales, en otras incluyen el nombre del autor. 
individuos y un sistema deshumanizante. El individualismo y la burguesía se asocian con la muerte o la inmovilidad. Cuando se representa a la burguesía, se refuerza el carácter crítico de la descripción, como cuando se dice en la contraportada de la novela Fuegos artificiales de Germán Marín, que el narrador mostraba -en un cuento ganador de un concurso literario"un desdén por el comportamiento burgués, cifrado en ciertos personajes abúlicos, retóricos y noctámbulos". Si la novela de Marín habla acerca de la burguesía, se sostiene que se trata de una "clase que comienza su derrumbe", proponiendo una interpretación del desarrollo histórico de una clase social que remite al discurso de lucha de clases propio de la UP.

A esta valoración de lo popular y denostación de lo burgués, corresponde una oposición a nivel formal. Neruda, en la "Explicación perentoria" que precede a Incitación al Nixonicidio y alabanza de la revolución chilena, pone en polos opuestos a los "exquisitos estéticos" y a los lectores populares mediante una metáfora culinaria: mientras que sus poemas pueden generar una indigestión a los esteticistas, son "buenos tal vez para la salud popular" (13). Lo formal se presenta en clave política, donde el arte por el arte se considera como algo ajeno a la lucha revolucionaria. Hay una evidente "feminización" de lo formal que se opone a lo revolucionario entendido como lucha masculina. En Banda de Pueblo, del ecuatoriano José de la Cuadra, se explica que la generación de escritores a la que pertenece el autor (la 'generación de 1930'), "dista mucho de ser una literatura refinada y estetizante", puesto que surgió "al calor de una agitada lucha social" de donde provendría su "inusitado vigor" que le permite ser "arma de combate y de solidaridad con la causa popular" (5). Tal vez esta dicotomía obliga al autor anónimo del texto de presentación del libro Reunión, de Cortázar, a resolver la contradicción que presentaba un autor de izquierda caracterizado por los "experimentos formales" de novelas como Rayuela o 62 Modelo para Armar y por vivir fuera de América Latina hace años. El autor reafirma a Cortázar al señalar que este "no se ha descomprometido jamás de nuestro continente, intentando describir las variedades dolorosas y gloriosas de vivir en una realidad como la nuestra", señalando que su última obra publicada, El Libro de Manuel, "denuncia las torturas y la represión de las dictaduras gorilas" (5-6). Cortázar -quien además generosamente cede los derechos de autor a Quimantú- se vuelve así presentable para el público.

En la vereda opuesta, sin asomo de incomodidad, destaca el "orgullo" con que Quimantú presenta "la última obra del poeta mayor del idioma y de la raza, quien convierte en ella su poesía en rayo vengador, en tormentado fuego" (solapa Incitación al Nixonicidio). El tono enardecido deja ver el pleno reconocimiento a la figura de Neruda, cuyo compromiso arrastra al paratexto en su lucha y deja de lado el didactismo políticamente cauto de otras publicaciones literarias. Las preguntas sobre los medios de alcanzar la nueva cultura se suspenden en la medida en que Neruda parece personificarla.

A pesar de que en ocasiones se valora lo universal -como cuando Bartleby es presentado como un "estudio de profunda significación psicológica y de alto valor emotivo y humano" y a Melville como un "río oculto [donde] se desliza el prodigioso misterio de la vida y la muerte" (5-7)-, lo cierto es que esta universalidad aparece si no subordinada, al menos en un lugar de menor relevancia con respecto a la valoración de la revolución 
como proceso de cambio político y social. Este es el foco principal de la antología de Poesía combatiente. Grandes poetas del siglo XX, ${ }^{17}$ prologada por Guillermo Quiñones, quien afirma que "el rasgo más sobresaliente de la poesía de los últimos cincuenta años es el esfuerzo tenaz de innumerables poetas de todos los ámbitos por vincular sus mundos internos con la vida del pueblo, sus clamores, sus luchas" (9). La contratapa es aún más explícita al señalar que de esta poesía "surgen la exaltación de la revolución, del revolucionario y la visión esperanzada del mañana" (contratapa). El vínculo que se establece entre poesía revolucionaria y esperanza implica proyectar la producción literaria a un futuro, cuestión que también puede pensarse en relación a las colecciones literarias de Quimantú en general.

\subsection{Políticas hermenéuticas del paratexto}

Las colecciones literarias de Quimantú transitan entre el rescate de la estabilidad de la tradición -proponiendo eso sí un marco de lectura que familiariza la crítica al capitalismo y la revolución como proceso político, social y cultural- y la proyección de un futuro propiamente revolucionario. Se traza así un arco temporal en que la literatura, desde la tradición, se proyecta como indicio de los cambios deseados. En este sentido, y acercándose al concepto de partínoost, resulta interesante cómo, en ocasiones, las obras literarias publicadas son presentadas mediante una hermenéutica contingente. Mediante esta, la literatura se lee en relación a eventos históricos en desarrollo. Se ofrece al lector un marco de lectura que vincula interpretación literaria y proceso revolucionario chileno. La literatura es así un síntoma del proceso social. Las características de la obra se explican mediante analogías con los conflictos de poder y políticos que oponen a la burguesía y al proletariado en Chile.

El mejor ejemplo de esta hermenéutica contingente lo da Ariel Dorfman, que prologa El ciclista del San Cristóbal, de Antonio Skármeta, publicado en la colección Quimantú para todos en mayo de 1973 con un tiraje de 30 mil ejemplares. Dorfman explicita la necesidad de "poner esos cuentos en el momento histórico dentro del cual se escribieron" (10). La ternura, el amor, la sensualidad y la locura anticipan y expresan, para Dorfman, "las presiones para un cambio de sistema social que se venía gestando en la sociedad chilena y que encuentra su fructificación en la victoria de la Unidad Popular en 1970" (10). Se politiza la alegría en oposición a un "viejo sistema autoritario", propio del "moralismo barato de la burguesía" (10-11). En oposición a las críticas que Dorfman realizaba de revistas como Readers Digest o el colonialismo de publicaciones infantiles como

\footnotetext{
${ }^{17}$ Es curioso cómo, en esta antología, coexisten poetas como Mistral, Neruda y Parra. Al final, se incluye una breve biografía en que se explica el aporte revolucionario de cada uno. De Mistral se destaca, por ejemplo, su premio Nobel de 1945 y su "amor por los seres humildes" (205), lo que la acercaría a la valoración de lo popular. De Neruda, en cambio, se señala que "logró derribar la discriminación política" (205), lo sin duda hace mención a la persecución política de la que fue víctima y cómo, a pesar de eso, logra el Premio Nobel en 1971. De Parra, en cambio, se omite la publicación de los Artefactos en 1972 y su abierta crítica al proceso revolucionario chileno. Se prefiere, simplemente, rescatar su origen "chillanejo" y su condición de "antipoeta" (205).
} 
Babar, la aparición del libro de Skármeta es celebrado como una posibilidad de expresar "todo lo que aparece de nuevo y hermoso" (12), es decir, la revolución parece requerir de un nuevo lenguaje que de cuenta de la realidad que se despliega "sin tener que recurrir a enciclopedias o revistas extranjerizantes" (12).

Este aparecer revolucionario se acompaña, en el cuento "El Cigarrillo", del surgimiento de un personaje antirrevolucionario, "un traidor a su clase social, [...] un mercenario al servicio de la burguesía" (12). Si bien esto podría considerarse como una representación que obstaculiza la revolución o que abre la puerta a plantear dudas sobre ella, Dorfman prefiere interpretarlo como un ejemplo de cómo "un escritor comprometido con un proceso de cambios va transformando su propia obra a medida que varía su existencia misma" (13). El vínculo con la contingencia política se explicita aún más cuando Dorfman vincula el surgimiento de este traidor a la "toma del Poder Ejecutivo por la Unidad Popular" (13). Ahí donde el personaje antirrevolucionario podría causar sospechas sobre la verdadera mirada del autor sobre el proceso político, Dorfman sugiere que este personaje es "el enemigo que se resiste en el interior de cada uno de nosotros, ese traidor en que la burguesía quisiera convertirnos a todos" (13). En vez de traspasar la sospecha al autor-cuestión que se descarta en la medida en que en el resto de los cuentos predominan los "angelicales rebeldes"-, Dorfman duda indirectamente de los lectores, asimilados a focos posibles de traición burguesa. Si bien Dorfman se incluye en ese nosotros, su misma inclusión como autor de prólogo en la editorial estatal pareciera eximirlo de cualquier cuestionamiento. La política de democratización de la lectura se enfrenta aquí al peligro de la diversidad política (entendida binariamente como compromiso o traición) del público lector al que, sin embargo, se busca llegar.

Así como Dorfman expresa la confianza de que la producción literaria de Skármeta muestra "los frutos literarios más inmediatos de este proceso chileno que estamos viviendo" (13), Neruda parece enfatizar los riesgos que experimenta. Si bien se alaba la revolución chilena, esta se ve amenazada política y económicamente tanto en el interior como en el exterior. En ese contexto, Neruda propone una visión en que la poesía sublima las frustraciones del proceso revolucionario chileno. Imposibilitado de modificar una correlación de fuerzas adversa, Neruda prefiere refugiarse en la "capacidad demoledora de la Poesía" para enfrentar al adversario político internacional que Nixon representa. El poder de Nixon aparece a la vez como un peligro y como inalcanzable, por lo que "sólo los poetas son capaces de ponerlo contra la pared y agujerearlo por entero con los más mortíferos tercetos" (8). Si Nixon pretende "aniquilar la revolución chilena", Quimantú pone a disposición una obra que ofrece la posibilidad sublimada de enfrentarse imaginariamente con el adversario.

En los distintos casos, se observa que la literatura se propone más como un reflejo de problemas sociales que al servicio de la creación de una cultura nueva. No se aborda directamente el rol del lector popular como creador potencial de una literatura popular y revolucionaria. Tampoco se explicitan como tales las diferentes miradas en torno al rol de la cultura y de los intelectuales en la creación de una nueva cultura socialista. No hay una comunicación directa al lector acerca de la necesidad de reparar una desigualdad de acceso a la cultura. Las colecciones literarias de Quimantú operaron 
como un espacio de intervención para intelectuales en que tenía lugar un juego de apariencias: por un lado, mostrar cierta ecuanimidad crítica y familiaridad revolucionaria; por otro, la afirmación de un determinado modo de leer literatura que reflejara, a su vez, un modo de pensar el rol de la cultura en el proceso revolucionario chileno. Las colecciones de literatura como espacio de intervención cultural de distintas posturas sobre política cultural permiten entender la coexistencia de autores y voces antagonistas en el debate público. La presencia de Enrique Lihn como antologador de los Diez cuentos de bandidos es interesante en este sentido. Lihn, que había criticado públicamente la detención de Padilla en Cuba, y cuyas críticas a ciertos aspectos de la política cultural de la UP podían entenderse como dirigida también a las colecciones literarias de Quimantú, aprovecha el espacio paratextual para plantear matices con respecto al carácter ideológico de la literatura. Para Lihn, es evidente que un mismo tema -el bandolerismo en este caso- se modifica históricamente y constituye un soporte para expresar diversas ideologías. Una antología, dice, es un lugar ideal para observar filiaciones ideológicas de los escritores, aunque "no siempre [...] con idéntico grado de conciencia respecto de la causa por la cual abogaban" (5-6). Al introducir la posibilidad de inconciencia ideológica con respecto a la causa que se piensa defender, Lihn parece desconfiar de la idea de una literatura ideológicamente coherente con el compromiso personal hacia una determinada línea política. En cambio, Lihn sugiere una mayor complejidad en torno a la relación entre escritura e ideología, cuando afirma que "un escritor puede expresar la mentalidad de una clase de muchas maneras distintas", subrayando que "el modo mismo de contar una historia -la técnica narrativa- constituye una fuente de indicios mucho más profunda" para intentar entender esta relación. Sin embargo, como si Lihn se diera cuenta de que esa idea abre un espacio de debate e incluso de polémica, señala que "no [se] va a meter aquí en este tipo de profundidades..." (6). Lihn utiliza el espacio paratextual para reflexionar sobre la relación entre escritura e ideología, planteando preguntas sobre ella más que señalando pertenencias ideológicas establecidas, lo que contrasta con el obcecado esfuerzo de Dorfman haciendo coincidir la producción de Skármeta con un proceso revolucionario en desarrollo.

\section{Conclusión}

Distintos intelectuales adherentes a la UP ensayan formas de acercar la literatura al horizonte revolucionario en el paratexto de las colecciones literarias. Se modela una lectura basada en indicios de la decadencia burguesa o de la promesa del cambio por venir. Este acercamiento es a la vez un espacio de reflexión sobre las relaciones entre literatura y sociedad, entre escritor y revolución. El conjunto produce un efecto coral ligeramente disonante, donde se revela la diversidad de miradas en torno a la política cultural más que el alineamiento a una política central inexistente. Los prólogos y las presentaciones cumplen una función de mediación con respecto al público lector al que se quiere llegar, pero simultáneamente constituyen una escenificación indirecta de los diálogos del campo 
literario en torno a las formas de abordar la literatura y su relación con el cambio social. Estos paratextos omiten el propósito ideológico que se planteaba para las colecciones de literatura en los medios de comunicación. De alguna forma, esto muestra que las colecciones literarias de Quimantú fueron un proyecto pensado desde la élite intelectual. El horizonte sin clases sociales de la UP choca con la incomodidad de la clase intelectual ante el rol que puede tener la lectura literaria en la política cultural. A pesar de que el programa de la UP apuntaba a que el pueblo sería el actor principal de la nueva cultura, la literatura en Quimantú ponía al pueblo en posición de consumidor. Quimantú para todos y los Minilibros (más que Cordillera sin duda) democratizaron la literatura y propusieron un modo de leerla que hacía plausible su rol como reflejo de los procesos sociales y como expresión del horizonte revolucionario. El traspaso de la tradición y la relectura del canon se consideran como una etapa previa del surgimiento de la cultura socialista por venir. Más allá del posible paternalismo del gesto de Quimantú, es indudable su preocupación por hacer accesibles obras y problemas a un sector antes marginado del mercado del libro. Por primera vez, los lectores populares podían participar de este mercado y descubrir no solo literatura de distintos países y períodos, sino también, a través de los prólogos y presentaciones que acompañaban las ediciones, modos de lectura literaria que acercaban de diversas formas la literatura a la revolución.

\section{Obras citadas}

Austin, Robert. 2003. The State, Literacy, and Popular Education in Chile, 1964-1990. Oxford: Lexington Books.

Bajtín, Mijail. 2012. Las fronteras del discurso. Buenos Aires: Las Cuarenta.

Bergot, Solène. 2004. "Quimantú: Editorial del Estado durante la Unidad Popular chilena (1970-1973)". Revista Pensamiento Crítico 4: 2-25.

Berríos, María. 2003. "Presentación del tema 'Cultura”, en Rodrigo Baño (ed.), La Unidad Popular treinta años después. Santiago: Universidad de Chile.

Bianchi, Soledad. 1995. La memoria: modelo para armar. Santiago: DIBAM-Centro de Investigaciones Diego Barros Arana.

Bowen, Martín. 1995. "El proyecto sociocultural de la izquierda chilena durante la Unidad Popular. Crítica, verdad e inmunología política”. Nuevo Mundo Mundos Nuevos (2008). Web 18 agosto 2016.

Bowker, Geoffrey y Star, Susan. 2000. Sorting Things Out. Classification and Its Consequences. Cambridge-London: The MIT Press.

Carrasco, Iván. 2008a. "Ambivalencia identitaria en la literatura chilena canónica". Estudios filológicos 43: 55-62.

. 2008b. "Procesos de canonización de la literatura chilena". Revista Chilena de Literatura 73: 139-161.

Casanova, Pascale. 2008. La république mondiale des lettres. París: Seuil.

Cisternas, Enrique. 2014. "Fuegos fugaces y mundanos: recorrido y fracaso de Fuegos artifi- 
ciales de Germán Marín", en Acero, Nibaldo y otros (eds.). Vestigio y especulación. Textos anunciados, inacabados y perdidos de la literatura chilena. Santiago: Chancacazo. 66-99. Dorfman, Ariel. 2016. Ensayos quemados en Chile. Buenos Aires: Ediciones Godot.

Dorfman, Ariel y Mattelart, Armand. 2010. Para leer al pato donald. Comunicación de masas y colonialismo. México D. F.: Siglo XXI.

Genette, Gérard. 2001. Umbrales. Buenos Aires: Siglo XXI Editores.

Groys, Boris. 2008. Obra de arte total Stalin. Valencia: Pre-textos.

Gutiérrez, Joaquín. 1972. "Todos seremos lectores. Entrevista”. Chile Hoy 10: 21.

James, Vaughan. Soviet Socialist Realism. Origins and Theory. London: Palgrave MacMillan, 1973.

Jobet, Jorge. 1972. "La política Editorial de Quimantú. Entrevista del sábado a Luciano Rodrigo". La Nación, 22 abril: 3-4.

Koselleck, Reiner. 2012. "Revolución como concepto y como metáfora. Sobre la semántica de una palabra en un tiempo enfática", en Historias de conceptos. Estudios sobre semántica y pragmática del lenguaje politico y social. Madrid: Trotta. 161-170.

Latour, Bruno y Woolgar, Steve. 1996. La vie de laboratoire. La production des faits scientifiques. París: La Découverte.

Lihn, Enrique. 1997. "Política y cultura en una etapa de transición al socialismo", en $E l$ circo en llamas. Santiago: LOM ediciones. 436-466.

López, Hilda. 2014. Un sueño llamado Quimantú. Santiago: Ceibo ediciones.

Maldonado, Carlos. 1972a. “¿Dónde está la política cultural?”. Quinta Rueda 1: 12-13. . 1972b. "El proceso cultural como incentivador de la praxis". Cuadernos de la realidad nacional 12: 69-83.

Marinello, Juan Cristóbal. 2007. "Quién es Chile. La visión de lo nacional en la colección 'Nosotros los chilenos' de la Editora Nacional Quimantú, 1971-1973”, en Seminario Simón Collier. Santiago: Pontificia Universidad Católica y LOM Ediciones. 9-39.

Ministerio de Educación de Chile. 1972. "Anexo 1. Documento preparado por el Ministerio de Educación como aporte al 'Congreso Nacional de Educación' - diciembre 1971”, en Revista de Educación 36-37-38: 71-98.

Molina, María Isabel; Facuse, Marisol y Yánez, Isabel. 2018. Quimantú: prácticas, politica y memoria. Santiago: Grafito Ediciones.

Pedemonte, Rafael. 2009. "Chile y la 'Guerra por las ideas': intercambios y vínculos culturales con la Unión Soviética (1964-1973)”, en Seminario Simón Collier 2008. Santiago: Instituto de Historia Pontificia Universidad Católica de Chile. 13-50.

Programa Básico de Gobierno de la Unidad Popular. 1970.

Rama, Ángel. 1984. "El boom en perspectiva", en Más allá del boom. Literatura y mercado. Buenos Aires: Folios ediciones. 51-110.

Schaeffer, Jean-Marie. 1983. La naissance de la littérature: la théorie esthétique du romantisme allemand. París: Presses de l'Ecole Normale Supérieure.

Subercaseaux, Bernardo. 2000. Historia del libro en Chile (Alma y cuerpo). Santiago: LOM ediciones. 
2007. Historia de las ideas y la cultura en Chile. Nacionalismo y cultura. Tomo IV. Santiago: Editorial Universitaria.

Teitelboim, Volodia. 1973. "5.000.000 de libros”. La Quinta rueda 4: 3.

Zamorano, César. 2016. "La revista Cormorán y su contribución al debate en torno a la cultura en la Unidad Popular". Izquierdas 30: 215-235.

Zarowsky, Mariano. 2009. "Políticas culturales y comunicación popular en el gobierno de Salvador Allende. La intervención política intelectual de Armand Mattelart". $V$ Jornadas de Jóvenes Investigadores. Buenos Aires: Instituto de Investigaciones Gino Germano, Facultad de Ciencias Sociales, Universidad de Buenos Aires.

\section{Libros de LAS COLECCIONES DE LITERATURA DE QUimantú CitAdos}

\section{Colección Minilibros}

Alcalde, Alfonso. 1973. Las aventuras de El Salustio y El Trúbico. Santiago: Quimantú.

Alvarado, Edesio. 1973. La captura. Santiago: Quimantú.

Andreiev, Leonidas. 1973. La risa roja. Santiago: Quimantú.

Cortázar, Julio. 1973. Reunión. Santiago: Quimantú.

De la Cuadra, José. 1973. Banda de Pueblo. Santiago: Quimantú.

Melville, Herman. 1973. Bartleby. Santiago: Quimantú.

\section{Quimantú para todos}

Diez cuentos de bandidos. 1972. Santiago: Quimantú.

Neruda, Pablo. 1973. Incitación al Nixonicidio y alabanza de la revolución chilena. Santiago: Quimantú.

Poesía combatiente. Grandes poetas del siglo XX. 1973. Santiago: Quimantú.

Skármeta, Antonio. 1973. El ciclista de San Cristóbal. Santiago: Quimantú.

\section{Cordillera}

Marín, Germán. 1973. Fuegos artificiales. Santiago: Quimantú. 